\title{
Preservación del patrimonio documental digital en el mundo y en México
}

\author{
Juan Voutssás M.*
}

Artículo recibido:

17 de abril de 2008.

Artículo aceptado:

23 de febrero de 2012.

\section{RESUMEN}

Se analiza la evolución de los principales proyectos de preservación documental digital a nivel mundial, destacando sus premisas y elementos más relevantes, así como diversas estrategias que se han desarrollado para su posible preservación. A partir de ello, se hace una propuesta de una posible estrategia a nivel nacional para empezar a desarrollar proyectos de preservación documental digital de forma coordinada y armónica orientados a este propósito.

Palabras clave: Bibliotecología, Ciencias de la información, Bibliotecas y archivos digitales o electrónicos, Preservación documental digital, Evolución

* Centro Universitario de Investigaciones Bibliotecológicas de la UNAM, México. voutssas@unam.mx

INVESTIGACIÓN BIBLIOTECOLÓGICA, Vol. 26, Núm. 56, enero/abril, 2012, México, ISSN: 0187-358X. pp. 71-113 
y desarrollo de la preservación digital, Estrategias para la preservación digital en México.

\section{ABSTRACT \\ Preservation of Digital Documentary Heritage in the World and in Mexico \\ Juan Voutssás $M$.}

The paper discusses the evolution of the main projects of digital document preservation globally, highlighting its premises and most relevant elements, as well as various strategies that have been developed for its possible preservation. From this, is a proposal for a possible national-level strategy to begin developing digital document preservation projects in a coordinated and harmonious way aimed at this purpose.

Keywords: Library Science, Information Sciences, Digital or Electronic Libraries and Archives, Documentary Digital Preservation, Evolution and Development of the Digital preservation, Strategies for Digital Preservation in Mexico.

\section{INTRODUCCIÓN}

$\mathrm{T}$ odos los grupos y conglomerados humanos, todas las regiones y países poseen riquezas documentales que necesariamente hay que preservar y distribuir. Forman en esencia su patrimonio cultural. Es impensable no considerarlo y no tratar de preservarlo. Por lo mismo, en diversas partes del mundo se han iniciado una serie de esfuerzos tendientes a darle forma y estructura a ese patrimonio documental de diversas regiones y comunidades, así como a la creación de una memoria documental, tanto en los soportes tradicionales como en los nuevos soportes digitales. Es así que en sociedades avanzadas en las Tecnologías de Información y Comunicación-TIC- se observa muy claramente la preocupación de ir creando una memoria documental digital para la generación actual y las futuras. Este fenómeno puede verse ya claramente en la Unión Europea, Los Estados Unidos de América, los países nórdicos, Canadá, Australia, etcétera. Todas estas regiones están diseñando estrategias que les permitan, por una parte, colectar todo su patrimonio cultural escrito, filmado o grabado, de tal forma que pueda ser preservado y 
distribuido vía la red. La problemática que se desprende en estos proyectos es formidable; no pueden ser enfrentados a nivel de organizaciones aisladas ya que sin duda rebasa sus capacidades; debe ser solucionada a nivel de naciones, regiones o grandes consorcios, con la participación de múltiples sectores públicos y privados. En cuanto a personas que participen en ellos, sucede lo mismo; este tipo de proyectos deben ser tratados con enfoques trans y multidisciplinarios. Se requiere del concurso de planeadores, legisladores, ejecutivos, gobernantes, profesionales del cómputo, de la bibliotecología y la archivonomía, editores, proveedores, etcétera, para emprender un adecuado diseño y puesta en marcha de algún plan coherente.

A tal efecto, muchas cuestiones deben irse planteando y resolviendo ¿cuánto material hay para digitalizar?, ¿cuál conviene digitalizar?, ¿quién debe hacer qué parte?, ¿cómo repartirlo?, ¿cómo evitar que se pierda lo que es originalmente digital; es decir, páginas Web, publicaciones y comunicados electrónicos, etcétera?, ¿quién es el responsable de guardarlo?, ¿cuáles son los factores que incidirán en la preservación a largo plazo? Creo que muchas de estas preguntas pueden contestarse a través de la última: los factores que inciden en la preservación. Tales factores pueden agruparse de varias formas para su estudio. En lo personal yo los agrupo en seis categorías: Factores culturales, tecnológicos, legales, documentales, económicos y sociales; veámoslos en forma sucinta.

Los factores culturales tienen que ver con la falta de sensibilidad de ciertas sociedades en ciertas épocas respecto al valor histórico de partes de su patrimonio documental, lo cual lleva a excluir la necesidad de guardar o archivar ese patrimonio y al final deriva en la pérdida de ese acervo documental. Nuestra época, contrariamente a lo que se pudiera pensar -se afirma que vivimos en la "sociedad de la información"-, tiene en forma general un enorme problema de tipo cultural con respecto a la preservación de la información electrónica, una especie de oxímoron cultural.

Los factores tecnológicos tienen que ver con el cambio rápido y constante de los dispositivos y aspectos tecnológicos relacionados con la información electrónica. Se afirma hoy en día que el problema ya no es conservar los bits, sino cómo hacer que sean legibles en un futuro, dados esos cambios tecnológicos ajenos a la información documental en sí pero indispensables para hacerla legible; estos son los factores relacionados con el entorno de esa información digital, tales como el equipo y los programas que se requieren para reproducirlos. Mención aparte requieren los sistemas operativos y múltiples formatos que se han ido creando para la representación de diversos documentos digitales en todos sus tipos: texto, audio, imagen estática y en movimiento, etcétera, y que surgen y desaparecen con rapidez cada vez mayor. 
Dentro de los factores tecnológicos se encuentran además los relacionados con la seguridad de la información: ¿cómo se evitará que se pierdan por accidente o error registros en los acervos de preservación?, ¿cómo se garantiza su integridad evitando que manos no autorizadas sustraigan, destruyan o alteren esos registros?

A continuación tenemos los factores de tipo legal alrededor de la información; de suma importancia en proyectos de esta naturaleza, puesto que es indispensable lograr un adecuado balance entre el derecho a la información y el derecho de autor. ¿Quién puede guardar qué? y ¿si puede guardarlo, puede distribuirlo o no?, ¿'en qué medida?, ¿cómo y cuándo?, ¿quién puede copiar qué y hasta dónde? Los preceptos de las bibliotecas nacionales y su depósito legal han sido sobreimpactados en unos pocos años. ¿Deben hacer esto ellas? Si es el caso, debemos crear entonces el entorno que les permita hacerlo. Pero además ¿pueden distribuirlo?, ¿a quién y hasta dónde? y si no son ellas las responsables, ¿entonces quién lo es? y ¿qué va a pasar con los libros, revistas y periódicos digitales que hoy sólo están en propiedad de sus editores?, ellos no los van a conservar en-línea para siempre, no es su función. Hay cambios constantes a nivel global en los las leyes acerca de copyrights o derechos de copia ¿cómo quedan los derechos al acceso y sobre todo a la preservación en este contexto digital? Si no hacemos algo coherente al respecto, dadas las excesivas restricciones de derechos y la falta de políticas al respecto, nadie guardará nada y en unas pocas décadas enormes cantidades de publicaciones estarán perdidas para siempre.

En este mismo orden de ideas acerca de los factores legales debe hacerse también una reflexión acerca de los derechos de acceso a la información en correcto balance con el derecho a la privacidad de las personas: chasta dónde puede distribuirse la información sin lesionar la privacidad de alguien? Poco está escrito al respecto y ya se observan fenómenos muy complejos y realmente preocupantes, desde el caso del spam en la red hasta el acoso y la divulgación de información personal. Peter Lyman ha establecido ya algunas premisas interesantes a este respecto.

Otro de los factores que se está discutiendo ampliamente hoy en día dada su enorme importancia, tiene que ver con el registro y los metadatos que deben ser agregados a estos acervos; éste es uno de los factores documentales; de nada sirve preservar millones y millones de documentos digitales si luego no van a poder ser encontrados. ¿Cuáles son los metadatos adecuados para cierto tipo de documento?, ¿cómo se buscará en conjuntos no homogéneos de colecciones con metadatos distintos?, ¿cuáles son los metadatos mínimos?, ¿cuáles los óptimos?, ¿cómo debe ser la interoperabilidad actual de datos, formatos y sistemas para que todo siga interoperando en el futuro? todo esto 
debe ser establecido junto con los proyectos de preservación; de otro modo el esfuerzo será estéril. En los factores documentales existe además la discusión de cómo debe ser en sí un documento digital "pertinente".

Respecto a los factores sociales debemos pensar en cómo vamos a poder garantizar el acceso y la usabilidad documental. Es necesario establecer los mecanismos para que en un futuro se pueda tener acceso efectivo y masivo a esa información por parte del público. De nada sirve preservar por preservar si nadie tendrá acceso a ella. Salvados los derechos, propiedades y restricciones correspondientes, el reto futuro será cómo hacer llegar esa información digital a un número mayor de personas en el mundo sin crear nuevas brechas segregacionistas. Recuérdese todo lo que se ha debatido ya en este momento acerca de la "brecha digital" y sus consecuencias a futuro. Debemos crear las infraestructuras para que sea posible que las personas tengan acceso a esa información y que la brecha tienda a cerrarse y no al contrario. Puede abundarse un poco más en este tema de la brecha en mi obra anterior "Un Modelo de bibliotecas Digitales para México"; ${ }^{1}$ y si se desea conocer más a fondo este problema, recomiendo la obra de Adolfo Rodríguez al respecto. ${ }^{2}$

Finalmente, un proyecto de estos alcances debe reflexionar insoslayablemente en materia de costos ¿cuánto cuesta hacer qué cosa?, ¿quién tiene la responsabilidad de costear la preservación de acervos documentales?, ¿ cómo pueden lograrse economías? Estos no son nunca proyectos baratos ni de corto plazo, esa es la razón por la que deben establecerse minuciosamente los elementos económicos que deben verse involucrados en el desarrollo de los mismos para hacerlos y mantenerlos viables, económicamente hablando. Y por caros que sean, debe recordarse siempre también a la hora de costear, que no preservar sale a la larga todavía más caro.

Como puede observarse, el problema es complejo porque los factores son variados y requieren de múltiples enfoques. Un plan o proyecto de este tipo requiere ser analizado desde distintos puntos de vista, y aproximaciones que vayan respondiendo adecuadamente a las múltiples preguntas que en este apartado se han planteado. Si no son todas las cuestiones que caben en este tema, me parece que son las más relevantes. Ésta ha sido sólo una introducción a los seis factores en los que agrupo todos los elementos relacionados con la preservación a fin de tener una idea de los mismos. Los he tratado con más detalle en dos artículos al efecto.

1 Juan Voutssás M., 2007, Un Modelo de Planeación de Bibliotecas Digitales Para México, México: UNAM, Centro Universitario de Investigaciones Bibliotecológicas, 309 p., ISBN: 970-324111-5., págs. 60-66.

2 Adolfo Rodríguez G., 2006, La brech a digital y sus determinantes, México: UNAM, Centro Universitario de Investigaciones Bibliotecológicas, 254 p., ISBN: 970-32-3853-X. 
Como he mencionado, puede observarse claramente que a nivel mundial la preocupación y los proyectos tendientes a estudiar y trabajar esta problemática han ido en aumento. En cambio, en nuestro país, tan carente de proyectos estratégicos de largo alcance en materia de contenidos digitales relacionados con tecnologías de información, no existe ningún proyecto, plan, iniciativa ni organización trabajando a gran escala en este rubro. Todo lo que existe son proyectos puntuales a nivel de ciertas instituciones puntuales. Reitero, nada estratégico ni de alcance nacional. Y las instituciones que tienen entre sus misiones la de preservar acervos documentales, lo hacen principalmente con sus soportes "tradicionales"; muy rara vez o muy poco en porcentaje, en lo relativo a documentos digitales. El factor cultural nos afecta gravemente para empezar. De ahí que sea sumamente importante sentar las bases de una propuesta que permita insertarnos en este tipo de proyectos y crear los cimientos de un proyecto -o proyectos- de esta naturaleza para México, con el objeto de que en su momento los tomadores de decisiones y planeadores en nuestro país tengan algún antecedente del problema y sus posibles soluciones, adecuadas a nuestra problemática nacional, nuestra estructura, contexto y recursos.

\section{EVOLUCión DE LA PRESERVACIÓN DIGITAL EN EL MUNDO}

La problemática de la preservación documental derivada del uso de nuevas tecnologías surge desde épocas previas a la información digital, pero se agrava con el advenimiento de la información electrónica en las primeras décadas de las computadoras y se agudiza todavía más con la llegada de los documentos digitales de la década del Internet. Cada generación moderna de nuevos soportes de preservación de material documental -simplemente nuevos métodos de "fijado" "manifestación" o "instanciación"- ha introducido una serie de variables y circunstancias que han sido consideradas en su momento en diversos países o regiones, para tratar de ir poniendo cierto orden dentro del caos introducido por estos avances en la tecnología. Su estudio es importante porque vistas en conjunto contextualizan y resumen muy bien el estado del arte de las iniciativas de gran escala en diversos países o regiones y sirven por supuesto para tratar de establecer una tendencia de lo que debiese hacerse hoy en día en nuestro país.

El primer antecedente de esta problemática en tiempos modernos surgió desde 1978 en la unión americana a iniciativa de Warren J. Haas, quien era presidente del Council on Library Resources, CLR. Dado que él había sido bibliotecario en jefe de la Universidad de Columbia, padecía muy de cerca los 
problemas de los libros quebradizos de la colección del siglo XIX de esa universidad. Y consciente de que se trataba de un problema nacional, impulsó la creación de un grupo especial de estudio al efecto en unión con la Asociación de Universidades Norteamericanas -Association of American Universities-. Este grupo, formado por académicos y bibliotecarios expertos, hizo un diagnóstico detallado del problema y sentó las bases para futuros planes acerca del tema de la preservación a nivel nacional. En 1985, el grupo recomendó la formación de una organización permanente y especializada al efecto. Al año siguiente se estableció la "Comisión Para la Preservación y el Acceso" -Commission on Preservation and Access- ó CPA. Patricia Battin, entonces encargada de la biblioteca en Columbia, fue nombrada primera presidenta de la CPA. Esta organización, trabajando muy de cerca con el "Fondo Nacional para las Humanidades de los E.U.A." -U.S. National Endowment for the Humanities ó $\mathrm{NEH}-$, fue la que desarrolló la estrategia nacional para realizar de conversión masiva de libros a microfilmes, ya mencionada en otros apartados.

Iniciando un poco después de la CPA se creó el "Consorcio de Preservación Digital”, Digital Preservation Consortium -DPC-. ${ }^{3}$ Este organismo fue formado a principios de los años noventa por un grupo de universidades norteamericanas que trabajaban conjuntamente tanto a nivel de instituciones como de académicos para conseguir un uso efectivo de los materiales preservados en formato digital. Cabe resaltar que estos primeros pasos en la digitalización y preservación de material digital son anteriores al advenimiento de la Internet. La misión de este consorcio era desarrollar el uso y la utilidad de la tecnología digital con objeto de preservar e implementar el acceso a obras intelectuales de importancia nacional e internacional. Las universidades miembros de este consorcio fueron: La Universidad de California, la del Sur de California, la de Stanford y la de Berkeley; las universidades de Columbia, Michigan, estatales de Pennsylvania y de Tennessee, así como las de Harvard, Yale, Cornell y Princeton. Éstos son los objetivos que en 1994 se propusieron para los siguientes cinco a diez años, y que alcanzaron con mayor o menor éxito:

- Definir, estudiar y promover el adecuado uso de las imágenes digitales para su preservación y acceso.

- Definir y promover métodos y criterios compartidos, para producir, almacenar y distribuir imágenes digitales.

- Ampliar la base de materiales preservados en forma de imágenes digitales.

3 Commission on Preservation and Access. 1996. "The Digital Preservation Consortium Mission and Goals". Sitio oficial del "Council on Library and Information Resources - CLIR". Disponible agosto, $2008 \mathrm{en:} \mathrm{http://www.clir.org/pubs/reports/dpcmiss/dpcmiss.html}$ 
- Desarrollar y mantener mecanismos fiables que garanticen el acceso generalizado a documentos digitales de imágenes.

Este organismo se convirtió un poco más adelante en la conocida Digital Libraries Federation o Federación de Bibliotecas Digitales, la que lanzó la Primera Iniciativa en Bibliotecas Digitales, como ya fue comentado. De hecho, los resultados no fueron tan importantes como la misión presentada en ese entonces, a pesar de lo cual, la DLF sentó las bases para enfrentar proyectos de digitalización muy importantes en la unión americana, que a su vez han influido notoriamente en posteriores proyectos de preservación digital. En la actualidad, los Estados Unidos han vuelto a desencadenar otro enorme proyecto cooperativo con miras a la preservación masiva y de largo término de su patrimonio documental electrónico, encabezado por la Biblioteca del Congreso de los EUA, a través de un programa denominado Programa nacional de infraestructura y preservación de información digital, "The National Digital Information Infrastructure and Preservation Program", NDIIPP. ${ }^{4}$ Este proyecto comenzó en 1998 como un primer paso para iniciar una estrategia digital que le permitiera a un grupo de expertos encargarse de definir los roles y responsabilidades de las bibliotecas en la era digital. Dicho grupo serviría para sentar las bases de la preservación digital. Para diciembre de 2000, sus actividades llevaron el proyecto a nivel de ley sancionada por el Congreso de los E.U.A., USA Public Law 106-554. ${ }^{5}$

El objetivo de esta ley ha consistido en desarrollar para beneficio de ésta y futuras generaciones de usuarios, una estrategia para recopilar, archivar y preservar contenido digital, sobre todo el que sólo existe en dicho formato y, por lo mismo, el considerado como el más vulnerable. El NDIIPP nació en la unión americana como respuesta a las recomendaciones de grupos de trabajos creados ad hoc por la Biblioteca del Congreso de los EUA, provenientes de la "Sociedad de Bibliotecarios para Iniciativas Estratégicas" -Associate Librarian for Strategic Initiatives-, la "Sociedad de Bibliotecarios para Servicios Bibliotecarios" Associate Librarian for Library Services, y la oficina de registro de derechos de autor -Register of Copyrights-, El "Consejo Nacional en Ciencias de la Computación y Telecomunicaciones" -National Research Council Computer Science and Telecommunications- y el Consejo de

4 Library of Congress, 2003, "NDIIPP: The National Digital Information Infrastructure \& Preservation Program", Sitio Oficial de la Biblioteca del Congreso de los E.U.A., disponible agosto, 2008 en: http://www.digitalpreservation.gov/library/program_back.html

5 United States Congress, 2000, "National Digital Information Infrastructure and Preservation Program”. Public Law 106-554, 106th Congress, December 14th, 2000, disponible agosto, 2008 en: http://frwebgate.access.gpo.gov/cgi-bin/getdoc.cgi?dbname=106_cong_public_laws\&doc $\mathrm{id}=\mathrm{f}:$ publ554.106 
la Academia Nacional de Ciencias -National Academy of Sciences o NAS-. Ellos presentaron un documento titulado "A digital strategy for the Library of Congress" -2000-, el cual estableció como prioritaria la necesidad de impulsar un esfuerzo cooperativo nacional para archivar y preservar los recursos digitales más frágiles, que están en alto riesgo de desaparecer debido a múltiples amenazas tales como el deterioro de la información grabada en soportes digitales, y la rápida evolución de la tecnología causante de la obsolescencia de formatos, equipos de cómputo y programas. La Biblioteca del Congreso no debería emprender por sí misma proyectos específicos sino crear la infraestructura de instituciones socias, gubernamentales, y no implicarse en lo respectivo a arquitectura técnica, normatividad y legislación, pero sí buscar que esos socios definieran los proyectos que considerasen relevantes, prioritarios y viables.

Los socios representan a bibliotecas de diversos tipos, grandes editores de diversas clases de contenido: editorial, fílmico, periodístico, de entretenimiento, etcétera y a empresas clave en la búsqueda y gestión de información digital, como Google o Yaboo. La Biblioteca del Congreso trabaja también en colaboración con las bibliotecas nacionales de Canadá, Francia, Holanda, Australia, Dinamarca, los países nórdicos, Reino Unido y Brasil.

En los últimos años se ha logrado la creación de la red inicial de asociados y la definición de la estructura técnica; se han iniciado proyectos de investigación básica sobre la preservación digital acerca de materiales muy variados además de los típicos como textos e imágenes: sobre datos y estadísticas de investigación en ciencias sociales; sobre noticieros, datos geográficoespaciales, programación televisiva; sobre colecciones históricas multimedia; sobre archivos de empresas; sobre páginas Web de la administración pública y sobre temas políticos. Se prevé que en un par de años más, la primera fase de este proyecto haya concluido la elaboración de normas de preservación para la incorporación y la transferencia de contenido digital, y que habrá acumulado más de 100 Terabytes -1012 bytes- de documentos digitales.

En 1995, los directivos de CLR y CPA decidieron unir los esfuerzos de ambas organizaciones en una sola que cubriera de forma más integral los objetivos de ambas. Surgió así una importante organización en esta temática, el "Consejo de Recursos para la Biblioteca y la Información", -Council on Library and Information Resources - o CLIR, el cual ha impulsado, compilado y publicado una gran cantidad de documentos relativos al tema de la preservación documental, en especial la digital. ${ }^{6}$

6 "CLIR HISTORY", 2005, Sitio oficial del "Council on Library and Information Resources CLIR", disponible agosto, 2008 en: http://www.clir.org/about/history.html 
En términos generales, los cuatro objetivos expresados por el Consorcio de Preservación DCP se repiten y se encuentran en forma muy semejante en casi todos los otros proyectos posteriores en esta dirección. De esas cuatro premisas partirá también esta parte del análisis.

En años más recientes también los europeos han iniciado diversos trabajos con miras a la preservación digital. Como lo han hecho en muchas de sus actividades recientes, han planteado el problema a nivel de todo el continente y por lo mismo han planteado una solución integral como Unión Europea. Derivado de su programa general de desarrollo informático llamado e-Europe establecido a principios de este siglo, se creó la iniciativa "Digital Preservation Europe" -DPE-, la cual es la organización y propuesta enfocada a la solución de esta problemática. Este proyecto tiene tres objetivos principales, cada uno a su vez con sus metas correspondientes.

1. Crear una plataforma coherente para la cooperación proactiva, la colaboración, el intercambio y la diseminación de resultados y proyectos de investigaciones así como experiencias acerca de la preservación de objetos digitales.

1. Identificar y llamar la atención acerca de los factores relacionados con la curaduría y preservación de objetos digitales a lo largo del amplio espectro de las naciones y la región europea en lo relativo a su patrimonio cultural y científico.

2. Contribuir a evitar la duplicación de esfuerzos de investigación por parte de diversas comunidades y permitir identificar, recolectar y compartir el conocimiento y experiencia acerca del tema.

3. Crear un vínculo entre la comunidad investigadora y la comunidad de usuarios que impulse el trabajo colaborativo alrededor de las necesidades de preservación.

4. Estimular mayor investigación en la preservación digital en áreas clave así como fomentar el desarrollo de estándares donde hayan sido detectadas brechas y oportunidades.

2. Incrementar la existencia de servicios de preservación así como su viabilidad y solvencia económica.

1. Apoyar el desarrollo de una propuesta europea para auditar y certificar los repositorios europeos como un paso esencial para crear la gestión de contenidos y servicios entregables en forma de una federación de repositorios.

2. Estimular a las empresas de TIC, en especial desarrolladores de software, a incorporar algunos de los principios de la filosofía de preservación a las nuevas generaciones de software. 
3. Relacionar más la agenda de investigación en preservación documental con el desarrollo de productos utilizables en ese aspecto e implicar más a ambos sectores.

3. Optimizar la conciencia, habilidades y recursos alrededor de la preservación digital.

1. Establecer temas clave que desemboquen en líneas guías esenciales, así como métodos y herramientas que liguen la preservación con los sectores público y privado de Europa.

2. Implementar una serie de seminarios basados en las mejores prácticas identificando posteriores acciones de entrenamiento que debiesen ser desarrolladas. ${ }^{7}$

Como resultado de esta iniciativa, y entre varios proyectos derivados de ella, los europeos ya han logrado instrumentar el proyecto de la "Biblioteca de Depósito Europea en Red", "Networked European Deposit Library" o NEDLIB. Este proyecto fue impulsado por el comité CoBRA+, un comité permanente de la Conferencia de Bibliotecas Nacionales Europeas, Conference of European National Libraries o CENL. Ocho Bibliotecas y un archivo nacionales europeos, así como tres grandes editores de la región participaron en el proyecto, el cual coordinó la Real Biblioteca Nacional de Holanda. Este proyecto ha tenido por objetivo desarrollar un marco estructural común a todos sus integrantes así como herramientas básicas computacionales que permitan construir un sistema de depósito de publicaciones electrónicas dentro de estas bibliotecas y archivos. Éste es un excelente ejemplo de lo que puede hacerse cooperativamente entre bibliotecas nacionales, archivos nacionales y editores, y es un proyecto internacional. Sienta las bases de lo que puede y debe ser una cooperación para el depósito, -legal o voluntario- de las publicaciones electrónicas. Este es el tipo de proyecto que es sumamente útil para tomarlo como punto de referencia en proyectos que deberían hacerse a nivel de México como país e inclusive como región latinoamericana. Puede abundarse más al respecto en su sitio Web: http://nedlib.kb.nl/

Otro proyecto europeo interesante en el mundo de la archivística es el denominado MoReq. A partir del impulso dado por el Foro Europeo "Document Lifecycle Forum", DLM Forum, especialmente a través de su plan de trabajo, conocido como "Diez puntos de seguimiento". La Comisión Europea decidió desarrollar un modelo de requisitos para la gestión de documentos electrónicos. MoReq es un conjunto de requisitos funcionales destinados

7 Digital Preservation Europe, 2006, "DPE Objectives", Sitio oficial de la DPE, disponible agosto, 2006 en: http://www.digitalpreservationeurope.eu/about/objectives/ 
a facilitar el diseño y la evaluación de los Sistemas de Gestión de Documentos Electrónicos de Archivo -SGDEA- o ERMS por sus siglas en inglés: Electronic Records Management System, sobre todo en el ámbito de los archivos de gestión gubernamental.

El objetivo de MoReq fue definir de forma general las características que debe tener una "aplicación destinada a la gestión de documentos electrónicos de archivos, tradicionales o digitales". Está formado en primera instancia por una serie de procedimientos y políticas definidos en buena parte por las expectativas, usos, perspectivas y exigencias normativas propias de cada organización o país, y en segunda instancia y en menor medida, por los programas de software o herramientas utilizadas en la gestión documental. MoReq se ocupa, fundamentalmente, del primero de los componentes: definir los requisitos funcionales de la gestión de documentos electrónicos de archivo en el seno de un sistema de gestión de documentos electrónicos, y después en definir aquellas funcionalidades que debe cumplir el software destinado a la gestión de documentos electrónicos de archivo. En total MoReq reúne 390 requisitos y 127 elementos de metadatos, que tienen como finalidad garantizar que los documentos electrónicos de archivo producidos por una organización se gestione adecuadamente con vistas a su preservación y disponibilidad a lo largo del tiempo. Moreq ha devenido con el tiempo en la norma Norma ISO 15489 [Comunidad Económica Europea, 2001].

Como parte de este conjunto de iniciativas europeas alrededor del patrimonio digital cabe destacar el proyecto de la Biblioteca Digital Europea o "Europeana", esfuerzo que es la cima de la iniciativa conocida como eContentplus. Esta biblioteca digital fue puesta en servicio recientemente con un conjunto de más de dos millones de documentos digitales europeos: libros, mapas, grabaciones, documentos de archivo, fotografías, pinturas y películas de toda la Comunidad Económica Europea. Se espera que para el año 2010 ofrezca más de diez millones de documentos convirtiéndose así en una formidable antología de la cultura y patrimonio de la región europea, así como en un ejemplo de iniciativas acerca del patrimonio documental digital a nivel regional. El sitio oficial de la biblioteca es: http://www.europeana.eu

En otros ámbitos, entre 2002 y 2003 fueron publicadas varias visiones de conjunto y de diversas naciones y/o regiones acerca del estado del arte relacionado con la preservación digital. Entre ellas destacan las directrices de la Unesco preparadas por Colin Webb de la Biblioteca Nacional de Australia para protección del patrimonio digital de las sociedades así como el ya mencionado programa NDIIPP, que incluye el conocido estudio de compilación de iniciativas de Neil Beagrie [Beagrie, 2003], quien trabaja en conjunto con la Biblioteca del Congreso de los EUA y el "Consejo de Recursos para la Biblioteca 
y la Información", Council on Library and Information Resources o CLIR. Beagrie identificó programas nacionales en Australia, Francia, los países bajos, y el Reino Unido que fuesen semejantes al esfuerzo - entonces naciente- de la iniciativa NDIIPP. En ese estudio reunió información a través de una serie de visitas, entrevistas y estudios de sitios Web existentes en el 2002, y describió sistemáticamente:

1. Cada programa, su contexto nacional, la misión y fundamento legal pertinentes cuando existían

2. Iniciativas y proyectos institucionales y nacionales

3. Iniciativas internacionales

4. Iniciativas planeadas o futuras internacionales

Beagrie extiende estas conclusiones con otros ejemplos que no son estrictamente nacionales en el alcance pero influyen en el tema ampliamente, como la "Open Archival Information System and Preservation Technology for European Broadcast Archives”.

En un ambiente más particular, Colin Webb fue el principal gestor del proyecto australiano de preservación documental, conocido como Preservation Metadata for Digital Collections de la National Library of AustraliaNLA-. El cual es uno de los más importantes a nivel mundial y como región.

Otras diversas agrupaciones internacionales como por ejemplo el Grupo de Trabajo de Archivo y Preservación Digital NSF-DLI [NSF-DLI, 2003], el Grupo de Trabajo sobre Atributos de Archivos Digitales del RLG [OCLC / RLG, 2001], y el Grupo de Trabajo de metadatos de Preservación de OCLC / RLG [RLG-OCLC, 2001], han tratado y publicado acerca de estos temas específicos y han ofrecido así una visión internacional de los desarrollos más importantes. En la actualidad estas dos organizaciones han lanzado el proyecto conjunto entre el Online Computer Library Center -OCLC- y el Research Libraries Group -RLG- denominado PREMIS -PREservation Metadata: Implementation Strategies-.

Existen también en el medio otras publicaciones importantes dirigidas a organizaciones y administradores, proporcionándoles directrices y recomendaciones sobre cómo administrar sus recursos digitales con énfasis en la preservación. En esta misma dirección, recientemente, observamos también el surgimiento del proyecto "ERA" -Electronic Records Archives- dependiente de la NARA -National Archives and Records Administration- o Agencia Nacional para la Administración de Archivos y Registros en la Unión Americana. Este plan es parte de un plan estratégico para crear "medios comprensibles, 
sistemáticos y dinámicos para preservar virtualmente cualquier clase de registro digital, independiente de cualquier hardware o software." 8

Regresando a las directrices de la Unesco para la protección del patrimonio digital de las sociedades, cuentan con numerosos puntos por demás interesantes, muchos de los cuales ya han sido discutidos aquí previamente. A continuación presento un resumen de lo más relevante de estas directrices y los capítulos que las abordan que, como puede observarse, conforman una base de lo más importante a tenerse en cuenta en este tipo de proyectos:

- Comprensión del Patrimonio Digital - Capítulo 6

Según la Unesco, conforman el patrimonio digital

los recursos informáticos únicos de valor perdurable, que son el fruto del saber o la expresión de los seres humanos y que son dignos de ser conservados para las generaciones futuras, procedentes de sectores, comunidades, industrias y regiones diferentes. Comprende por lo tanto: recursos de carácter científico, técnico, educativo, cultural, legal, médico, administrativo y de otras clases. Este patrimonio se encuentra en constante aumento, puede existir en cualquier lengua, en cualquier lugar del mundo y cualquier campo de la expresión o el saber humano.

Estos recursos pueden ser generados directamente en formato digital o convertidos a éste a partir de material ya existente en soportes "tradicionales". Textos, fotografías, bases de datos, imágenes fijas o en movimiento, grabaciones sonoras, material gráfico, noticias, documentos oficiales, programas informáticos o páginas Web, entre otros muchos documentos posibles dentro de un vasto repertorio de diversidad creciente. No todos los documentos digitales poseen un valor permanente, pero cuando es el caso, constituyen por ello un material digno de protección y conservación en beneficio de las generaciones actuales y futuras, a pesar de su soporte más "efímero".

Su preservación deberá estar orientada a:

- Permitir el acceso del público a ese material documental.

- Minimizar los riesgos que puedan ocasionar la pérdida de la información.

- Adoptar medidas en los más diversos ámbitos y en todos los ciclos

8 National Archives and Records Administration, 2003, ERA Project, Sitio Oficial del proyecto, disponible agosto 2008 en: http://www.archives.gov/about/plans-reports/strategicplan/2003/index.html 
vitales de la información digital, desde su creación hasta su utilización, que aseguren la continuidad del patrimonio digital en el tiempo.

\section{- Comprensión de la Preservación Digital - Capítulo 7}

La preservación digital plantea nuevos desafíos para las disciplinas de la conservación y el mantenimiento documental. Si aceptamos que la preservación está orientada a largo plazo, nos encontramos con un primer problema: la información digital no ha sido diseñada sino hasta hace poco para su manutención a lo largo del tiempo. En los materiales sobre soportes "tradicionales" los síntomas del deterioro son más evidentes, ya que tienden a ir desapareciendo de manera gradual y van desvaneciéndose o degradándose con el paso del tiempo y su custodio puede por tanto tomar medidas correctivas oportunamente. La información digital no se pierde de manera paulatina, simplemente existe o no. En el caso del patrimonio digital, la mayoría de las veces, en el momento en que se detectan estos síntomas la información ya se ha perdido irreparablemente. Esto obliga al custodio a desenvolverse proactivamente debiendo estar siempre un paso adelante a la manifestación del deterioro. En la conservación tradicional se está orientado primordialmente a garantizar la estabilidad del soporte; en el caso de la conservación digital, la obsolescencia de los sistemas operativos o ambientes, de los programas -softwares-, del equipamiento - hardware- y de los formatos, puede darse con mayor velocidad que la degradación del soporte en sí, y por tanto la conservación está orientada más al contenido. Más aún, está orientada a garantizar la accesibilidad y reproductibilidad permanente de los documentos digitales. Para ello es imperativo encontrar las maneras de representar lo que se les había presentado originalmente a los usuarios mediante un cambiante conjunto de equipos y programas informáticos que permitan procesar adecuadamente los datos. Para lograrlo es necesario que la comprensión y la gestión de los objetos digitales se realice considerándolos desde cuatro puntos de vista: como fenómenos físicos, como codificaciones lógicas, como objetos conceptuales comprensibles para el ser humano y como conjuntos de elementos esenciales que deben ser preservados para ofrecerles a los futuros usuarios esa esencia del objeto original.

- Comprensión de los sistemas computacionales de preservación digital Capítulo 8

Los sistemas computacionales deben tomar el control de los objetos digitales en forma apropiada y garantizar que permanecerán comprensibles y 
utilizables como copias auténticas. Por lo general, ello supone transferir los materiales, correctamente preparados, junto con la documentación o los metadatos asociados a ellos, a un sistema archivístico de almacenamiento digital, de forma tal, que puedan ser procesados sin riesgo de pérdida de datos o por cambios tecnológicos. Estos sistemas deben contar por tanto con características o atributos en los que se puede confiar para lograr una preservación digital permanente en lo referente a permanencia, viabilidad, adecuación a obsolescencia, autenticidad, interoperabilidad, seguridad, precisión, eficiencia, etcétera.

- Comprensión del trabajo interinstitucional en equipo y del valor de colaborar con los productores - Capítulos 11 y 13

Las colecciones digitales suelen crearse sin tener en cuenta el valor de uso y la accesibilidad permanente de los objetos que las componen. No obstante, existen o se pueden crear normas y prácticas que los productores pueden utilizar y que, según el caso, facilitarán o dificultarán la preservación. Los responsables de proyectos de preservación deben tratar de ejercer una influencia positiva lo antes posible en el ciclo de vida del patrimonio digital, lo que supone una voluntad de colaborar concertadamente con los productores. Además, existen muchas razones técnicas, económicas y políticas para que los programas de preservación diseñados a lo largo de varias instituciones o sectores cooperen entre sí. Las decisiones de colaboración deben basarse en la evaluación de los beneficios esperados y de los costos correspondientes, y en su caso, distribuidos. Existen varias razones para buscar socios y decidir las posibles bases de la relación así como los marcos estructurales que pueden ser aplicados. Una cooperación exitosa es por lo general consecuencia de una cuidadosa planeación, instrumentación y seguimiento de los esfuerzos intersectoriales o interinstitucionales.

- Comprensión de los documentos que vale la pena conservar - Capítulo 12

Ninguna institución, por muchos recursos que tuviese destinados a la conversión y preservación digital de sus colecciones, podrá asumir el costo que representa la preservación de la totalidad del patrimonio digital. Es necesario por tanto decidir qué materiales digitales vale la pena conservar, como siempre se hizo con los materiales en soportes tradicionales. Muchos de los procedimientos comunes, como la selección basada en criterios contenidos en las políticas de desarrollo de las colecciones y el buen conocimiento de los materiales, su contexto, la 
comunidad usuaria, etcétera, son fundamentales para hacer una adecuada selección del patrimonio digital. Los programas de preservación también deben definir los elementos o las características que les dan valor a los materiales seleccionados para que puedan ser conservados. En la preservación digital, se hace indispensable agregar además un valor de uso de la información digital en los criterios de selección.

- Atención a la gestión y equilibrio de los derechos - Capítulo 15

Las diversas partes interesadas en el patrimonio digital gozan de diversos derechos y tienen expectativas propias que los proyectos de preservación deben tomar en cuenta y de ser necesario, incluirlos en su plan de gestión. La mayoría de esos derechos tienen implicaciones legales, comprendidos los derechos de propiedad intelectual, los derechos en materia de respeto de la privacidad y los derechos de acceso a la información, teniendo en cuenta que los programas de preservación deben copiar objetos digitales para preservarlos, y que la inmensa mayoría de ellos buscan proporcionar algún tipo de acceso permanente e igualitario a esa información, se necesitan estrategias activas de gestión y equilibrio de los derechos, tanto a nivel social como legislativo y económico.

- Protección de los datos - Capítulo 16

La adecuada protección de los datos es fundamental en cualquier proyecto de preservación. Otro aspecto de capital importancia es la autenticidad, que guarda estrecha relación con la integridad permanente de los datos y con su identificación precisa y duradera, así como disponer de una documentación clara sobre los orígenes, historia y transformaciones de los materiales digitales. Por lo mismo la clara asignación de las responsabilidades, la infraestructura tecnológica, el mantenimiento, la transferencia y la renovación de datos, el almacenamiento adecuado de los soportes, el sistema de copias de seguridad, la seguridad interna de los sistemas y la prevención contra catástrofes, forman parte de la estrategia de protección de datos.

- Mantener la accesibilidad-Capitulo 17

Los sucesivos cambios que experimentan los equipos informáticos, sistemas operativos, programas y formatos provocan la pérdida del acceso al patrimonio digital. Muchos coinciden en que éste es el principal problema que deberán afrontar la mayoría de los proyectos de preservación. Basados en los conocimientos de la relación entre los objetos digitales y sus medios de acceso, y considerando lo que hay que presentarle a un usuario al proporcionarle acceso, los responsables de 
tales proyectos deben decidir cuáles estrategias podrán garantizar mejor la accesibilidad siempre que se necesite, pues todas éstas están aún en formación y seguramente seguirán cambiando con el tiempo y según las necesidades. Las estrategias ahora presentadas se han agrupado como sigue: las que se basan en la inversión de recursos desde el principio del ciclo de vida de los materiales digitales, las de vigencia a corto, mediano o largo plazo, y las alternativas no digitales, como la microfilmación; pero seguramente irán surgiendo nuevas estrategias al respecto.

Hasta aquí el resumen. El texto completo de las directrices puede leerse en el sitio oficial de Unesco, [Web, Colin. 2003].

\section{ANÁLISIS}

Con lo anterior podemos tratar de hacer un análisis en lo que respecta a la preservación digital en sí, su contexto y sus posibilidades dentro de nuestro medio nacional. Como estrategia a nivel país, no necesitamos volver a inventar la rueda. Como ha podido observarse, existen estrategias ya trazadas: hay muchos proyectos e iniciativas a nivel de países o regiones de los cuales pueden obtenerse abundante información y experiencia. Por supuesto, no se trata de calcar algún proyecto y reproducirlo exactamente. Todo deber ser contextualizado y adaptado a nuestra realidad nacional, a nuestras necesidades y a nuestras capacidades, pero las grandes estrategias están ahí ya marcadas. Cuando estemos inmersos en un proyecto o proyectos de esta naturaleza, seguramente podremos hacer nuestra aportación al conocimiento mundial en esta temática: tenemos la capacidad intelectual, técnica, económica y organizativa para lograrlo; y podemos por tanto desarrollar tecnología y conocimiento al respecto, aunque no sería éste nuestro principal objetivo, sino resolver el problema de nuestra preservación documental. Pero ambos objetivos pueden lograrse a la vez si sabemos cómo hacerlo.

En primer lugar, me parece que debemos recalcar el porqué de esta preservación, ¿cuál es su importancia? y ¿por qué debemos destinarle recursos a proyectos de esta naturaleza en estos tiempos y en este país? Para poder responder esto hemos discutido a lo largo de esta obra los aspectos culturales y sociales de la preservación digital. Como ya hemos mencionado, el primer tipo de factor que afecta la preservación de documentos digitales está conformado por el factor cultural. Los principales elementos en este factor son la falta de sensibilidad y entendimiento del problema. Como sociedad global 
ha sido solamente en los últimos años cuando hemos empezado a estar realmente conscientes de lo que el problema representa, y de lo que puede causar en relación a la pérdida del patrimonio documental digital si no tomamos las medidas adecuadas al respecto. Y esta conciencia es sólo incipiente, sobre todo en México, y por lo mismo debemos llevarla a más sectores y a más personas; en particular a aquellos que pueden hacer algo al respecto: tomadores de decisiones, planeadores, legisladores, editores, bibliotecarios, archivistas, etcétera. Y esto no es simplemente por amor a la cultura: la importancia para nuestro país es que forma parte de las condiciones para su propio desarrollo estratégico. Recordemos a qué aspiramos cuando hablamos de una "sociedad del conocimiento mexicana” y por qué aspiramos a ello:

Las sociedades del conocimiento están relacionadas con las capacidades para identificar, producir, procesar, transformar, difundir y utilizar información destinada a crear conocimientos y aplicarlos en beneficio del desarrollo humano. Esto supone respetar un conjunto de principios y prioridades: 'libertad de expresión, acceso universal a la información y al conocimiento, respeto de la dignidad humana y la diversidad cultural y lingüística, educación para todos de buena calidad, realización de inversiones en ciencia y tecnología, y entendimiento e incorporación de los sistemas de conocimiento autóctonos'.

Este objetivo se basa en los "once principios" fundamentales emitidos en la cumbre mundial de Unesco en 2003 al respecto de este tema y que deben regir la construcción de una "sociedad del conocimiento", y de entre los cuales extraigo y subrayo lo siguiente: [World Summit..., 2003].

\section{La función de los gobiernos y de todas las partes interesadas en la promoción de las TIC para el desarrollo}

Los gobiernos, el sector privado, la sociedad civil, las Naciones Unidas y otras organizaciones internacionales tienen una función y una responsabilidad importantes en el desarrollo de la sociedad del conocimiento y, en su caso, en el proceso de adopción de decisiones. Crear una sociedad de la información cuya prioridad sea la persona supone un esfuerzo conjunto que necesita de la cooperación y la asociación de todas las partes interesadas.

\section{Acceso a la información y al conocimiento}

El hecho de que todos puedan acceder y contribuir a la información, las ideas y el conocimiento es indispensable en una sociedad de la información 
incluyente. Es posible mejorar el intercambio y el incremento de los conocimientos mundiales para favorecer el desarrollo, si se eliminan las barreras que impiden un acceso equitativo a la información para realizar actividades económicas, sociales, políticas, sanitarias, culturales, educativas y científicas, y si se facilita el acceso a la información que existe en el dominio público. Éste es un factor capital del crecimiento de la sociedad de la información, ya que genera ventajas tales como un público informado, nuevos empleos, innovación, oportunidades comerciales y el avance de las ciencias. El acceso sin dificultad a la información del dominio público es esencial en la sociedad de la información, como lo es la protección de dicha información contra toda apropiación indebida. Habrá que fortalecer las entidades públicas tales como bibliotecas y archivos, museos, colecciones culturales y otros puntos de acceso comunitario para promover la preservación de los registros de documentos y el acceso libre y equitativo a la información. Nos habremos de esforzar en propiciar el acceso universal y equitativo al conocimiento científico y la creación y divulgación de información científica y técnica, con inclusión de las iniciativas encaminadas al acceso abierto en el campo de las publicaciones científicas.

\section{Creación de capacidades}

Hay que ofrecerle a toda persona la posibilidad de adquirir las competencias y los conocimientos necesarios para comprender, participar activamente y beneficiarse plenamente de la sociedad de la información y de la economía del conocimiento. La alfabetización y la educación primaria universal son factores esenciales para crear una sociedad de la información integradora para todos, teniendo en cuenta en particular las necesidades especiales de las niñas y las mujeres. A la vista de la amplia gama de especialistas en las TIC y la información, que serán necesarios a todos los niveles, debe prestarse particular atención a la creación de capacidades institucionales. Debe promoverse el empleo de las TIC a todos los niveles en la educación, la formación y el perfeccionamiento de los recursos humanos, teniendo en cuenta las necesidades particulares de las personas con discapacidades y los grupos desfavorecidos y vulnerables. La formación continua y de adultos, la capacitación en otras disciplinas y el aprendizaje continuo, la enseñanza a distancia y otros servicios especiales, tales como la telemedicina, pueden ser claves a la hora de beneficiarse de las nuevas posibilidades ofrecidas por las TIC para los empleos tradicionales, a profesiones liberales y las nuevas profesiones. A este respecto, la conciencia acerca de la importancia que revisten las TIC y la adquisición de conocimientos en esta esfera son un cimiento fundamental. 
Los creadores, editores y productores de contenido, así como los profesores, instructores, archivistas, bibliotecarios y alumnos deben desempeñar una función activa en la promoción de la sociedad de la información, particularmente en los países menos adelantados. Para alcanzar un desarrollo sostenible de la sociedad de la información, deben reforzarse las capacidades nacionales en materia de investigación y desarrollo de TIC. Por otro lado, las asociaciones entre países desarrollados y países en desarrollo, incluidos los países con economías en transición, con fines de investigación y desarrollo, transparencia de tecnologías, producción y utilización de los productos y servicios TIC, son indispensables si se desea propiciar la creación de capacidades y una participación mundial en la sociedad de la información.

La fabricación de productos para las TIC representa una oportunidad importante de creación de riqueza. El logro de nuestras aspiraciones compartidas para que los países en desarrollo y los países con economías en transición se conviertan en miembros eficaces de la sociedad de la información y conseguir que se integren positivamente en la economía del conocimiento, depende en gran parte de la mayor creación de capacidad en las esferas de la educación, los conocimientos técnicos y el acceso a la información, esferas todas ellas determinantes para el desarrollo y la capacidad de competencia.

\section{Entorno habilitador}

Para promover la sociedad de la información es indispensable crear un entorno propicio a nivel nacional e internacional; las TIC deben utilizarse como una herramienta importante de un gobierno eficaz. El imperio de la ley, acompañado por un marco de política y reglamentación propicio, transparente y favorable a la competencia, neutral desde el punto de vista tecnológico, predecible y que refleje las realidades nacionales, es insoslayable si se desea construir una sociedad de la información centrada en la persona. Los poderes públicos deben intervenir, según proceda, para corregir las fallas del mercado, mantener una competencia leal, atraer inversiones, fomentar el desarrollo de infraestructura y aplicaciones de las TIC para aumentar al máximo los beneficios económicos y sociales, y atender las prioridades nacionales. Las TIC son un importante factor habilitador del crecimiento, ya que mejoran la eficacia e incrementan la productividad, especialmente en las pequeñas y medianas empresas (PYMEs). Por esta razón, el desarrollo de la sociedad de la información es importante para lograr un crecimiento económico general en los países desarrollados y en desarrollo.

Se debe fomentar la mejora de la productividad por medio de las TIC y la aplicación de la innovación en todos los sectores económicos. La distribución 
equitativa de los beneficios contribuye a la erradicación de la pobreza y al desarrollo social. Las políticas que fomentan la inversión productiva y permiten a las empresas, en particular a las PYMEs, efectuar los cambios necesarios para aprovechar los beneficios de las TIC, son probablemente las más beneficiosas.

La mejor forma de promover el desarrollo sostenible en la sociedad de la información consiste en integrar plenamente los programas e iniciativas TIC en las estrategias de desarrollo nacionales y regionales.

\section{Aplicaciones de las TIC: ventajas en todos los aspectos de la vida}

La utilización y despliegue de las TIC debe orientarse a la creación de beneficios en todos los ámbitos de la vida cotidiana. Las aplicaciones TIC son potencialmente importantes para las actividades y servicios gubernamentales, la atención y la información sanitaria, la educación y la capacitación, el empleo, la creación de empleos, la actividad económica, la agricultura, el transporte, la protección del medio ambiente y la gestión de los recursos naturales, la prevención de catástrofes y la vida cultural, así como para fomentar la erradicación de la pobreza y otros objetivos de desarrollo acordados. Las TIC también deben contribuir al establecimiento de pautas de producción y consumo sostenibles y a reducir las barreras tradicionales, además de ofrecerles a todos la oportunidad de acceder a los mercados nacionales y mundiales de manera más equitativa. Sus aplicaciones deben ser fáciles de utilizar, accesibles para todos, asequibles, adaptadas a las necesidades nacionales en materia de idioma y cultura, y favorables al desarrollo sostenible. A tal efecto, las autoridades nacionales deben desempeñar una importante función en el suministro de servicios de TIC en beneficio de sus poblaciones.

\section{Diversidad e identidad culturales, diversidad lingüistica y contenido local}

La diversidad cultural es el patrimonio común de la humanidad; la sociedad de la información debe fundarse en el respeto de las identidades y las diversidades culturales y lingüísticas, las tradiciones y las religiones y estimular ese respeto, además de promover un diálogo entre las culturas y las civilizaciones. El fomento, la afirmación y preservación de los diversos idiomas e identidades culturales contribuirán a enriquecer aún más la sociedad de la información. La creación, difusión y preservación de contenidos en varios idiomas y formatos deben considerarse altamente prioritarias en la construcción de una sociedad de la información integradora, y prestarle particular atención a la diversidad del suministro de obras creativas y al debido reconocimiento de los derechos de los autores y artistas. 
Es esencial promover la producción de contenidos y la accesibilidad a éstos, sea con propósitos educativos, científicos o culturales o con fines recreativos, en diferentes idiomas y formatos. La creación de contenidos nacionales que se ajusten a las necesidades nacionales o regionales fomentará el desarrollo socioeconómico y estimulará la participación de todas las partes interesadas, incluyendo a los habitantes de zonas rurales, distantes y marginales. La preservación del patrimonio cultural es un elemento crucial de la identidad personal y del conocimiento de sí mismo, que son, a su vez, el enlace de una comunidad con su pasado. La sociedad de la información debe aprovechar y preservar el patrimonio cultural para el futuro, para lo cual debe utilizar todos los métodos adecuados, entre otros, la digitalización.

Tenemos la firme convicción de que estamos entrando colectivamente en una nueva era que ofrece inmensas posibilidades, es decir la era de la sociedad de la información y la expansión de la comunicación humana. En esta sociedad incipiente es posible generar, intercambiar, compartir y comunicar informaciones y conocimientos entre todas las redes del mundo.

Si tomamos las medidas necesarias, pronto todos los particulares podrán colaborar para construir una nueva sociedad de la información basada en el intercambio de conocimientos y asentada en la solidaridad mundial, y una mejor comprensión entre los pueblos y las naciones. Confiamos en que estas medidas abran una vía hacia el futuro desarrollo de una verdadera sociedad del conocimiento.

Los principios que he resumido en esta parte me parecen de capital importancia. Ellos son la brújula de la sociedad informatizada; sin ellos, se pierde el rumbo. Recordemos esta cuestión: ¿para qué queremos una sociedad del conocimiento? Ya está demostrado que el simple acceso a las TIC y a las redes no pone a sus beneficiarios en un plano superior. Deseamos y necesitamos que todas y cada una de las personas obtengan de ese acceso los mecanismos para propiciar el desarrollo de cada individuo informatizado y de su entorno social o todo será en vano. Hay que ofrecerle a cada persona la posibilidad de adquirir las competencias y los conocimientos necesarios para comprender, participar activamente y beneficiarse plenamente de la sociedad de la información y la economía del conocimiento; los miembros de esta sociedad deben poder capacitarse, aprender, desaprender y reaprender; deben estar informados y ser creativos. La utilización y despliegue de las TIC debe orientarse a la creación de beneficios en todos los ámbitos de la vida cotidiana, en lo personal y lo colectivo.

Es importante recalcar también que nuestro patrimonio documental mexicano, digital y no, forma parte del patrimonio universal, de la diversidad cultural del mundo, y que simplemente por eso es de suma importancia. 
No deseamos que se pierda ni se diluya. Deseamos que tenga su lugar en el universo documental de la red. Tomaré un par de párrafos de la "Declaración Universal Sobre la Diversidad Cultural" [Unesco, 2002] que me parece ilustran esta idea espléndidamente:

La cultura adquiere formas diversas a través del tiempo y del espacio. Esta diversidad se manifiesta en la originalidad y la pluralidad de las identidades que caracterizan los grupos y las sociedades que componen la humanidad. Fuente de intercambios, de innovación y de creatividad, la diversidad cultural es, para el género humano, tan necesaria como la diversidad biológica para los organismos vivos. En este sentido, constituye el patrimonio común de la humanidad y debe ser reconocida y consolidada en beneficio de las generaciones presentes y futuras. En nuestras sociedades cada vez más diversificadas, resulta indispensable garantizar una interacción armoniosa y una voluntad de convivir de personas y grupos con identidades culturales a un tiempo plurales, variadas y dinámicas. Las políticas que favorecen la inclusión y la participación de todos los ciudadanos garantizan la cohesión social, la vitalidad de la sociedad civil y la paz. Definido de esta manera, el pluralismo cultural constituye la respuesta política al hecho de la diversidad cultural. Inseparable de un contexto democrático, el pluralismo cultural es propicio a los intercambios culturales y al desarrollo de las capacidades creadoras que alimentan la vida pública.

La diversidad cultural amplía las posibilidades de elección que se nos brindan a todos; es una de las fuentes del desarrollo, entendido no solamente en términos de crecimiento económico, sino también como medio de acceso a una existencia intelectual, afectiva, moral y espiritual satisfactoria. La defensa de la diversidad cultural es un imperativo ético, inseparable del respeto a la dignidad de la persona humana. Ella supone el compromiso de respetar los derechos humanos y las libertades fundamentales, en particular los derechos de las personas que pertenecen a minorías y los de los pueblos autóctonos. Toda persona debe, así, poder expresarse, crear y difundir sus obras en la lengua que desee y en particular en su lengua materna; toda persona tiene derecho a una educación y una formación de calidad que respete plenamente su identidad cultural; toda persona debe poder participar en la vida cultural que elija y ejercer sus propias prácticas culturales, dentro de los límites que impone el respeto a los derechos humanos y a las libertades fundamentales

IFLA también se ha pronunciado en este aspecto. En las reuniones de debates de la Reunión Intergubernamental previa a la Convención para la Protección de la Diversidad Cultural y Expresiones Artísticas de Unesco, la IFLA estableció: 
Entre los valores fundamentales de IFLA está el de creer que las personas, las comunidades y las organizaciones del mundo requieren acceso universal y equitativo a la creación, producción y diseminación de información, ideas y obras intelectuales y artísticas para su bienestar social, educacional, cultural, democrático y económico.

De acuerdo con las estadísticas mundiales, las páginas en español ocupan el sexto lugar en número en la Web, con algo así como el $2.5 \%$ del total mundial; este porcentaje es demasiado poco si consideramos que el español es el tercer idioma más hablado del mundo, ya que lo habla el $6 \%$ de los habitantes del planeta. El segundo más hablado del mundo si consideramos a los que lo hablan como lengua nativa. Por otro lado, dentro de la red y a nivel mundial los usuarios hispanoparlantes ocupan el cuarto sitio con aproximadamente el $7.5 \%$ del total de usuarios. Cifra notable si consideramos que el segundo y tecer lugar son usuarios del lejano oriente, lo que nos ubica como el segundo conglomerado de usuarios en el hemisferio occidental, sólo después de los angloparlantes y sin embargo muy poco aún en comparación con ese grupo $-36.5 \%-$. Y debemos también estar conscientes de que nuestra responsabilidad es todavía más grande si consideramos que México es el país con mayor número de hispanoparlantes del planeta con 106 millones de habitantes, sin contar los compatriotas que habitan del otro lado de nuestras fronteras.

Pero eso no es todo. Además de nuestro idioma castellano, debemos considerar también el patrimonio documental en las muchas otras lenguas indígenas del país, -65 de acuerdo con las publicaciones oficiales-. Pocos países del planeta pueden ostentar tan exhuberante diversidad linguística. Y tanto en español como en estas lenguas, poseemos un legado cultural y documental que es necesario preservar para futuras generaciones; nadie más lo hará si no somos nosotros y en verdad sería un enorme déficit para la cultura universal si parte de esto se perdiera: arte, costumbres, tradiciones, expresiones, sincretismos, cocina y recetas, folklore, valores, formas de vida, música, ciencia y tecnología, humanidades, sociedad, etcétera; en suma, nuestra cultura mexicana; una inmensa pléyade de elementos que forman nuestra idiosincracia nacional y que deben ser registrados, protegidos e impulsados en proyectos para ese efecto, so pena de perder una buena parte de ese patrimonio cultural tan inusitadamente espléndido en nuestro país. Es el puente entre nuestro pasado y nuestro futuro así como entre nuestro patrimonio documental "tradicional" y digital. Como mexicanos deseamos ser integrados al ciberespacio, no homogeneizados en él; son dos cosas muy distintas y la llave maestra para lograrlo es la preservación e integración de nuestro patrimonio cultural el cual, en esencia, se manifiesta en documentos de toda índole: texto, imágenes, sonoros, etcétera. 
Podemos y debemos, por tanto, aspirar a una posible estrategia nacional para desarrollar e impulsar nuestra preservación documental. Para poder diseñarla creo que debemos apoyarnos en algunas de las numerosas ideas que hemos ido estudiando aquí. De entre ellas, rescato cuatro elementos básicos con los cuales trabajar de inicio. En primer lugar, los seis factores de la preservación:

- Culturales

- Tecnológicos

- Legales

- Documentales

- Económicos

- Sociales

En segundo lugar, las directrices del Digital Preservation Consortium:

- Definir, estudiar y promover el adecuado uso de los documentos digitales para su preservación y acceso.

- Definir y promover métodos y criterios compartidos para producir, almacenar y distribuir objetos digitales.

- Ampliar la base de materiales que están preservados en forma de objetos digitales.

- Desarrollar y mantener mecanismos fiables que garanticen el acceso generalizado a documentos digitales.

En tercer lugar, los tres puntos de "Digital Preservation Europe" -DPE-:

- Crear una plataforma regional coherente para obtener una cooperación proactiva y la colaboración, el intercambio y la diseminación de resultados y proyectos de investigaciones, así como requerir experiencias acerca de la preservación de objetos digitales.

- Incrementar la existencia de servicios de preservación así como su viabilidad y obtener solvencia económica.

- Optimizar la conciencia, habilidades y recursos relacionados con la preservación digital.

En cuarto lugar, nuestra estrategia Nacional precisará también de algunas de las directrices marcadas por la Unesco para proteger el patrimonio digital de las sociedades.

- Comprender el Patrimonio Digital.

- Comprender la Preservación Digital. 
- Comprender lo que son los sistemas computacionales de preservación digital.

- Comprender lo que significa el trabajo interinstitucional en equipo y el valor que tiene colaborar con los productores.

- Comprender cuáles son los documentos que vale la pena conservar.

- Atender lo que tiene que ver con la gestión y el equilibrio de los derechos de autor.

- Proteger los datos antes que desaparezcan.

- Mantener la accesibilidad a ellos.

Me parece que con estos cuatro elementos básicos podemos proponer una estrategia para desarrollar proyectos tendientes a la preservación de nuestro patrimonio digital.

Los seis factores básicos de la preservación nos son útiles en esta temática porque desde un punto de vista hermenéutico forman siempre un marco de referencia el cual, por lo mismo, nos permite explicar las relaciones existentes entre los fenómenos asociados a la preservación y el contexto en el que esos fenómenos acontecen. Además -y esto es muy importante- podemos usar los factores como marco de referencia tanto en proyectos estratégicos a nivel nacional o regional, como a nivel de proyectos puntuales dentro de una institución, algo así como una "lista de chequéo" - checklist- de los aspectos que debemos tener en cuenta dentro de la fase de planeación y ejecución del proyecto, para ayudarnos con esta lista de que no estamos dejando nada al azar. Si nos preocupamos -y nos ocupamos- de estos seis factores en nuestros proyectos de preservación digital estaremos maximizando las posibilidades de éxito del mismo.

Para microsistemas de bibliotecas o archivos digitales; es decir, sistemas locales de bibliotecas o archivos aislados o correspondientes a una institución o grupo de instituciones, los seis factores de la preservación permiten trazar estrategias y líneas de acción útiles para desarrollar proyectos de preservación dentro de ellas. Apoyándose a estos factores, cualquier profesional de la bibliotecología o archivonomía encargado de una biblioteca o archivo, o incluso de sistemas bibliotecarios o archivísticos institucionales, puede concebir un plan de acción de preservación digital bien planeado, estructurado, con rumbo y con idea para su biblioteca, archivo o conjunto de ellos dentro de su ámbito de acción.

Los seis factores cubren tres enfoques fundamentales en este tipo de proyectos: primero, los factores culturales y sociales nos dan el enfoque humanista del proyecto, que nos ayuda para poder ubicar los objetivos dentro del contexto social adecuado, la accesibilidad futura, los usuarios, la reducción de la 
brecha digital, etcétera. Segundo, los factores tecnológicos y documentales nos ayudan a enfocar, por un lado los aspectos relacionados con la tecnología de cómputo y las telecomunicaciones del proyecto, y por el otro la tecnología bibliotecológica y/o archivística que tienen que ver con el registro y la recuperación documental. El tercer enfoque nos recuerda los factores legales y económicos que nos permiten terminar de contextualizar el proyecto ayudándonos a enfocarlo alrededor de estos aspectos jurídicos y financieros del proyecto que tienen que ver con los intereses de editores y autores, con el financiamiento y con los costos, presupuestos actuales y proyectados a futuro, etcétera.

En segundo lugar, como mencionamos, podemos hacer uso de las directrices del Digital Preservation Consortium, las cuales nos permiten reflexionar cómo podemos empezar a organizar un plan estratégico a nivel país para organizar proyectos de preservación a nivel nacional o regional.

En esencia, estas directrices nos recuerdan las grandes líneas de acción que deben emprenderse para ir creando una infraestructura nacional con miras a hacer una preservación documental digital masiva, orquestada, y coherente: a definir, estudiar y promover tanto el adecuado uso de las imágenes digitales para su preservación y acceso, como los métodos y criterios compartidos para producir, almacenar y distribuir imágenes digitales. Tenemos que ampliar la base de materiales preservados en forma de objetos digitales así como desarrollar y mantener mecanismos fiables que garanticen el acceso generalizado a documentos digitales.

Tenemos que añadirles a estas directrices las establecidas en los tres puntos de arranque del proyecto "Digital Preservation Europe" -DPE-: Crear una plataforma regional coherente para la cooperación proactiva, la colaboración, el intercambio y la diseminación de resultados y proyectos de investigaciones así como las experiencias que se tengan acerca de la preservación de objetos digitales; incrementar la existencia de servicios de preservación así como su viabilidad y solvencia económica, y optimizar toda la conciencia, de las habilidades y los recursos que se tengan acerca de la preservación digital.

Basándonos en estos dos grupos de directrices, las americanas y las europeas, podemos deducir qué es lo que debemos hacer de arranque y, aunque no lo dicen expresamente, nos sugieren algo del cómo debe hacerse lo que nos proponemos: está implícito que debe crearse una organización nacional al efecto, tarea que no es nada fácil. El concepto de una organización para coordinar esfuerzos de preservación documental digital a nivel país no puede ser monolítico. Es natural y recomendable que a una organización de esta naturaleza, con cobertura nacional, deben concurrir muchos sectores y capas de nuestra sociedad por las razones ya expresadas a lo largo de esta obra. Y 
nunca he sido afecto simplemente a proponer la creación de una estructura administrativa para solucionar un problema. Por tanto reflexionemos un poco: básicamente ¿cómo debería ser esta organización para ser eficaz?

A mí me es útil imaginar estas organizaciones bajo la metodología del Pensamiento o Enfoque de Sistemas ya que éste es integrador, tanto en el análisis de las situaciones como en las conclusiones que nacen a partir de él, y puede proponer soluciones globales que exigen tener en consideración los diversos elementos y relaciones que conforman la estructura de lo que se define como "sistema", así como también todo aquello que conforme el entorno real del sistema definido.

Normalmente el enfoque es interdisciplinario, pero también puede ser transdisciplinario, lo que permite entender con mayor claridad y profundidad las necesidades, recursos y soluciones que rodean su objeto de estudio. Bajo este enfoque, debe analizarse el todo, así como los subsistemas o partes, pero también sus relaciones, interacciones, jerarquías, etcétera, y todo ello debe hacerse desde múltiples perspectivas. Sólo un amplio enfoque - holístico- de visión total del sistema aplicado a un objeto de estudio nos permitirá comprenderlo mejor y proponer soluciones más adecuadas y nos evitará perdernos en la maraña de visiones y soluciones aisladas, tan típico de este tipo de escenarios donde por lo general se aborda nada más una parte del problema. Sólo hay que recordar lo que ha sucedido con las enmiendas a las leyes de los derechos de propiedad, y los pegotes a los que ha dado lugar para tratar de extenderlas al mundo de la publicación digital: he ahí un excelente ejemplo de esta visión parcial que queremos evitar.

La razón fundamental de usar este enfoque sistémico obedece a la metodología misma, de este modo los problemas y soluciones pueden ser planteados tanto en términos teóricos y pragmáticos, como cualitativos y cuantitativos a la vez. A nivel "macro", es decir, país, nada me parece sencillo y seguramente sería bastante inexacto hacer un modelo teórico que explique el comportamiento y permita la predicción fenomenológica relativa a la preservación digital, y por ende lo que esta hipotética organización debería establecer como actividades prioritarias de preservación mediante un conjunto de leyes o principios fundamentales más allá de los objetivos de la organización trazados por las líneas directrices estratégicas ya enunciadas.

Usando una aproximación constructivista, un modelo es una herramienta de identificación y no debe tener carácter de absoluto, sino entenderse como un elemento provisional de acercamiento al entorno. La verdadera utilidad de un modelo es la posibilidad de combinarlo con otros recreando, de acuerdo con la necesidad, escenarios de ambientación del entorno. Lo atractivo de estos modelos radica en que permiten definir criterios de mediación 
entre el ente modelado y su contexto identificando sus características, patrones e interacciones; creando y recreando; e interpretando y reinterpretando el conocimiento. Con este punto de vista común en las aproximaciones constructivistas. Intentamos hoy tener presente que el conocimiento no es el resultado de una simple copia de una realidad preestablecida; es más bien un proceso dinámico e interactivo a través del cual la información externa es interpretada y reinterpretada por la mente al ir construyendo progresivamente modelos explicativos cada vez más complejos, sofisticados y deseablemente exactos. Por lo mismo, al tratar de conocer una realidad a través de los modelos que construimos para explicarla éstos deben ser siempre susceptibles de ser mejorados o cambiados.

Así, bajo este enfoque sistémico / hermenéutico concebimos un modelo de organización cuyos fines son producto de la construcción conjunta de sus miembros, lo que será mucho mejor para su futuro a mediano plazo. Me parece pues útil imaginar a esta organización no como un ente que tiene un fin absoluto y predeterminado, sino uno que puede tener diversos fines según la forma en que la vean los involucrados en su destino, surgiendo la variedad al interpretar la realidad. Esta visión será condicionada, ajustada y reacondicionada nuevamente por los intereses y valores de los involucrados en ella, al existir primordialmente un interés común centrado en la prevalencia de los objetivos y logros de la organización. A esta visión habrá que agregarle la trayectoria histórica de la organización conforme se vaya dando para condicionar periódicamente la situación actual de ese momento; enriqueciéndola con su experiencia del pasado y las aspiraciones futuras de sus miembros, quienes por lo mismo irán influyendo permanentemente en su comportamiento. En un momento dado, y como hemos observado en otras latitudes, esta organización podrá darse por terminada o crear a su vez otra u otras nuevas que hereden su experiencia y participantes y modifiquen sus objetivos y alcances. Desde mi punto de vista esta visión de la organización provisional interpreta mejor lo que sucede en el mundo real, y establece un modelo organizacional que es construido colectiva y permanentemente por los miembros de la organización a partir de sus interpretaciones evolutivas más dinámicas.

Se ha mencionado ya varias veces la participación multisectorial en el proyecto; conviene subrayar el porqué de ello: al hablar de organizaciones de alcance nacional o a un regional, en forma tradicional, como en muchos otros países, el gobierno mexicano ha tenido de forma casi exclusiva la responsabilidad de crear, organizar, sostener y financiar a la inmensa mayoría de las organizaciones del país; pero esta situación se observa cada vez menos en los modelos de otros países más avanzados, no económicamente hablando, sino en sus conceptos sobre la sociedad de la información, los cuales avanzan independientemente de la 
etapa de desarrollo económico en la que están. Ya he establecido mi postura en este sentido en otras obras y por ello no abundaré más al respecto.

Partiendo de los hechos incuestionables de que la información documental digital es un insumo sumamente valioso e indispensable para el desarrollo de nuestro país, y de que no es un insumo exclusivo del sector educativo o de la investigación académica, ni tampoco del sector gubernamental ni de los sectores productivos del país: financiero, industrial, comercial, energético, de servicios, etcétera; sino que se trata de un insumo común a todos estos sectores, ya que todos la generan, la consumen y en su caso deberán preservar una buena parte de ésta información, podemos establecer sin duda que existe un interés común y multisectorial en este insumo, y en lo que compete a nuestro tema, la preservación y el uso futuro de la información digital debe formar parte de las preocupaciones y necesidades de todos los sectores del país ya mencionados. Por supuesto, el gobierno tendrá que seguir asumiendo buena parte de esa responsabilidad, pero ya no podrá seguir siendo de su exclusiva responsabilidad. Por tanto el modelo futuro ideal de una organización nacional para la preservación de información digital será un proyecto de Estado y por ello conllevará el concurso del gobierno -sector educativo- y los sectores productivos.

La función del gobierno en un proyecto de esta índole será entonces la de fomentar, coordinar y regular, y no tanto la de ejecutar. De acuerdo con esta tendencia mundial, el sector gubernamental deberá crear cada vez más las condiciones para que la sociedad civil realice cosas en lugar de pretender realizar todo con base en sus propios recursos. Pero ello no debe interpretarse como que el gobierno ya no es responsable de la realización de proyectos de estrategia nacional, nada de eso; debe entenderse en el sentido de que el sector gubernamental propiciará, fomentará, regulará, supervisará, coordinará, etcétera. Es decir, habrá de velar para que las cosas se den, sin realizarlas él mismo, sin financiarlas totalmente y sin acabar teniendo el control absoluto de ellas, ya que en ese caso se vuelve el dueño y la única voz, con la serie de inconveniencias que la historia se ha encargado de mostrarnos que no terminan bien. Además de todo esto, el hecho de que no sea una organización permanente, implica muy poca infraestructura organizativa, y por lo mismo el presupuesto operativo puede ser mínimo y destinarles los recursos a los proyectos en sí, y no a la propia estructura administrativa. Esto es de suma importancia en nuestro contexto actual: no deseamos agregarle un elefante blanco más a nuestra colección nacional.

De este análisis pueden resaltarse las siguientes premisas: 
1) La organización nacional para la preservación del patrimonio documental mexicano no puede seguir siendo responsabilidad única del gobierno; es un proyecto de Estado que implica la concurrencia armónica del gobierno mexicano, el sector académico-educativo, los principales sectores productivos e incluso la misma sociedad civil.

2) El gobierno mexicano será responsable de su parte del desarrollo de manera integral; habrá responsabilidades federales, estatales y municipales, tanto de los poderes ejecutivos como de los legislativos. Deberá llegar a involucrar incluso a legislaciones, y usos y costumbres tanto regionales como locales. Cada una de los poderes y niveles del gobierno mexicano tendrá que poder establecer claramente sus responsabilidades y asumirlas.

3) El sector académico-educativo, por supuesto, formará parte de esta estructura. Aquí reside mucha de la información científica-académica que debe preservarse. Las universidades y las escuelas de bibliotecología y archivonomía son prácticamente las únicas entidades que forman los recursos humanos necesarios para alcanzar una preservación documental profesional, y por esta razón deben incrementar las capacidades de los recursos humanos del país respecto de la preservación digital. Además, una enorme parte de los acervos bibliográficos y archivos pertenecen a estos sectores, así que al igual que los demás sectores, deberán establecer cuidadosamente sus responsabilidades, recursos, características, niveles, subsectores, necesidades, operadores, fortalezas, retos, amenazas, etcétera, dentro del proyecto.

4) Muchos de los principales sectores productivos asociados all desarrollo del país serán también responsables de su parte, puesto que ellos también generan mucha información susceptible de ser preservada digitalmente y su opinión forma parte indispensable de este proceso: bancos, industrias, bolsa, fábricas, empresas, editores, sociedades autorales, por citar sólo algunos. Recordemos la problemática y las soluciones del depósito legal. Habrá de establecerse claramente, en el ámbito del proyecto nacional, quiénes son responsables de organizar cada uno de los sectores involucrados. Y cuáles son además sus necesidades de información, sus recursos documentales, características, organización, subsectores, posturas y opiniones, así como sus representantes, responsabilidades, etcétera.

5) El sector gubernamental, como productor y preservador de información digital se verá además beneficiado inmediata, directa y ampliamente por las recomendaciones, estándares, productos, tecnología, etcétera, emanados de una organización de esta naturaleza. 
Profundizo en esta última reflexión: a la fecha, el sector gubernamental es un enorme productor de información digital que cada día produce y almacena más y más información de este tipo y no tiene ningún estándar intersectorial, ninguna metodología estandarizada acerca de cómo preservar de manera orquestada sus diversos conglomerados de información. Cada subsector establece sus propios parámetros de preservación -cuando los llega a tener- sin ninguna sincronización intersectorial, con lo cual poner en riesgo cantidades inmensas de futura información gubernamental, riesgos que ya hemos comentado a lo largo de esta obra: Banco de México, SAT, INEGI, Suprema Corte de Justicia, Registros Públicos de Propiedad y Comercio, por citar algunos entre docenas, preservan cada vez más su información digitalmente, y cada uno emplea sus estándares internos, sean éstos buenos o no. Pero el gobierno como sector no coordina prácticamente nada internamente en este sentido, como se hace ya en otros países, y por tanto proliferan en las dependencias y poderes los estándares propietarios, y con ello la anarquía y el riesgo documentales en un futuro cercano. Pongo un ejemplo: hemos establecido previamente las características de un buen objeto digital con miras a la preservación; cabe una simple pregunta: ¿cuántos de los documentos digitales del sector gubernamental cumplen con esa definición? -o con cualquier otra siempre que sea estándar-. Puedo adelantar la no muy agradable respuesta: muchos documentos gubernamentales no la cumplen, con todo lo que ello implica para el futuro. Éste es un simple pero muy ilustrativo ejemplo de lo que podría beneficiarse este sector gubernamental si coordinara e impulsara una organización de esta naturaleza.

Retomando el tema de un proyecto y una organización nacional: para hacer la preservación documental digital sería necesario establecer antes un postulado básico; hago una propuesta a continuación sintetizando y adaptando el tema de la preservación, basándose en la "Declaración Universal de la UNESCO Sobre la Diversidad Cultural":

- Las múltiples formas de la cultura universal se manifiestan en la originalidad y la pluralidad de las identidades que caracterizan a los grupos y las sociedades que componen la humanidad. En particular, como nación mexicana, constituyen nuestro patrimonio común y por tanto deben ser reconocidas y consolidadas en beneficio de las generaciones presentes y futuras.

- La preservación del patrimonio cultural es un elemento crucial de la identidad personal y del conocimiento de nosotros mismos, los que son a su vez enlace con nuestras comunidades y con nuestro pasado. La sociedad del conocimiento mexicana y por tanto las colecciones digitales mexicanas deben aprovechar y preservar nuestro patrimonio cultural y heredándolo a las futuras generaciones. 
- Nuestra diversidad cultural amplía las posibilidades de elección que se brindan a todos; es una de las fuentes del desarrollo, no solamente en términos económicos, sino también como medio de acceso a una existencia intelectual, afectiva, moral y espiritual satisfactoria. Los garantes de la diversidad cultural son la libertad de expresión, el pluralismo de los medios de comunicación, el multilingüismo, la igualdad de acceso a las expresiones literarias y artísticas, al saber científico y tecnológico por parte de todas nuestras culturas — esto incluye también las versiones en documentos digitales-.

- Debe considerarse siempre el carácter específico de los bienes y servicios culturales que, en la medida en que son portadores de identidad, de valores y sentido, no deben ser considerados sólo como mercancías o bienes de consumo como los demás. La asignación de prioridades y evaluaciones nunca debe estar basada en la aplicación exclusiva de las reglas del mercado al sector cultural. Debe cuidarse con especial atención a la diversidad de la oferta creativa.

- A la vez que se fomenta y cuida el pluralismo cultural, debe procurarse siempre que éste mantenga también una identidad y unos valores como nación. Debemos estar conscientes siempre de que formamos parte de una nación inmensamente rica en lo cultural, plural, cósmica, en el significado de Vasconcelos. Deberá cuidarse que se vea esta pluralidad multicultural como la suma de lo que somos y de lo que nos une, nunca de lo que nos divide. La identidad dentro de la diversidad, la unión dentro de las diferencias, la riqueza que le da al todo la variedad de las partes, el orgullo de la pertenencia como individuos a una nación deben ser siempre el hilo conductor que le dé cohesión al tejido social y el valor supremo que nos dé forma como nación mexicana y a la vez cosmopolita

- Las acciones de impulso al patrimonio documental digital deben contemplar y estimular insoslayablemente este respeto de las identidades y diversidades culturales y lingüísticas, a las tradiciones y los valores, además de promover un diálogo entre las culturas y una identidad nacional. El fomento, la afirmación, el rescate y preservación de los diversos idiomas e identidades culturales indígenas contribuirán a enriquecer aún más a la sociedad del conocimiento mexicana. Es esencial promover a la vez la producción de contenidos y la accesibilidad a los mismos, sea con propósitos educativos, científicos, culturales o recreativos, en diferentes idiomas y formatos. La creación de contenido nacional que se ajuste a las necesidades nacionales o regionales fomentará el desarrollo socioeconómico y estimulará la participación de todas las partes interesadas, incluyendo a los habitantes de zonas rurales, distantes o marginadas.

Respecto al proyecto o programa al efecto, he aquí una propuesta de algo que podría llamarse: Programa de Preservación Documental Digital, cuyo postulado podría ser: 
El Programa de Preservación Documental Digital no es un proyecto de gobierno sino de Estado, y es por tanto integrador, y articula los intereses de los distintos poderes y niveles de gobierno, de las variadas entidades y dependencias públicas y privadas; de los de los miembros del sector académico-educativo; de los de los principales sectores productivos y hasta de las diversas instituciones de la misma sociedad civil, a fin de lograr ampliar lo más posible la preservación documental digital y la distribución de este patrimonio.

Como objetivo podemos establecer: que se generen alternativas de valor a través de acciones específicas cuyo fin ulterior y a largo plazo sea el de asegurar la permanencia y acceso del contenido de nuestro patrimonio nacional de documentos digitales, de forma permanente a tráves del tiempo y las tecnologías, independientemente de su soporte, formato o sistema.

Una de las primeras acciones podría ser la creación de una organización coordinadora al efecto, de la cual ya hemos estado tratando. Considerando que ya hemos mencionado las directrices del Digital Preservation Consortium y del "Digital Preservation Europe" las líneas directrices de arranque de esta organización nacional mexicana podrían ser:

- Optimizar la conciencia, habilidades y recursos nacionales alrededor de la preservación de nuestro patrimonio documental digital.

- Definir, estudiar y promover tanto los métodos, estándares buenas prácticas y criterios compartidos para la producción, almacenaje y distribución de documentos digitales, así como el adecuado uso y acceso de estos documentos digitales.

- Crear una plataforma nacional y regional latinoamericana coherente que propicie la cooperación proactiva, la colaboración, el intercambio y la diseminación de resultados y proyectos de investigaciones, así como experiencias acerca de la preservación de objetos digitales.

- Ampliar la base de materiales preservados en forma de objetos digitales así como desarrollar y mantener mecanismos fiables que garanticen el más amplio acceso generalizado a documentos digitales, a la vez que el absoluto respeto a los derechos autorales.

- Incrementar la existencia de servicios de preservación así como su viabilidad y solvencia económica.

Con objeto de alinear el programa y la organización a un marco de referencia internacional, y como fuente de políticas y premisas de la organización podríamos tomar de entrada algunas las directrices de la Unesco que se proponen proteger el patrimonio digital de las sociedades. Por ejemplo: 
- Comprender el Patrimonio Digital.

- Comprender la Preservación Digital.

- Comprender los sistemas computacionales de preservación digital.

- Comprender el trabajo interinstitucional en equipo y del valor de colaborar con los productores.

- Comprender los documentos que vale la pena conservar.

- Atender a la gestión y el equilibrio de los derechos.

- Proteger los datos y la información.

- Mantener la accesibilidad.

Obviamente, algunos de los primeros proyectos a desarrollar pueden salir de entre estas premisas. Y también, como ya hemos mencionado, el marco de referencia estratégico para todo tipo de proyecto emanado de esta organización puede estar conformado por los seis factores de la preservación:

- Culturales

- Tecnológicos

- Legales

- Documentales

- Económicos

- Sociales

Vale la pena subrayar que la organización está creada así para diseñar los marcos y las líneas estratégicas: el desarrollo de iniciativas y políticas de preservación digital, la organización de foros de discusión, las iniciativas para el desarrollo de estándares, el levantamiento de censos acerca del tema, la discusión de aspectos legales que impacten la preservación, el estado del arte de la preservación digital, las iniciativas para almacenar y proteger los datos e información de los recursos digitales, etcétera. $\mathrm{Y}$ a través de todo esto ir creando los "libros blancos" o documentación básica que puedan servir de cimentación nacional para arrancar un sinnúmero de iniciativas y proyectos ya específicos.

La organización en sí no debe desarrollar proyectos puntuales tal y como se ha hecho con otras iniciativas en otras regiones y países, $-\mathrm{y}$ ha comprobado ser una buena estrategia-, los proyectos puntuales pueden y deben ser encargados por la organización coordinadora a una o varias instituciones específicas considerando que ya tienen una infraestructura, y buscar ahí los recursos humanos, técnológicos y organizativos más idóneos para la tarea. Puede ser una secretaría de estado en particular, una paraestatal, una universidad, una biblioteca, un archivo, o cualquier conjunto de ellos. Para poder 
financiar esto específica y adecuadamente, los proyectos deben ser puntuales, finitos, y contar con resultados, tiempos y costos perfectamente medibles, apegados a estándares lo más abiertos y universales que sea posible, y entregar beneficios aprovechables de inmediato para amplios sectores.

\section{Consideraciones finales}

Es esencial que existan los medios que identifiquen y mantengan para siempre la información registrada. Sin ella, no habría registro del pasado, ni manera de identificar, entender o replicar la forma de vivir de la sociedad de un momento dado -en este caso nuestra sociedad contemporánea-, ni existirían los estudios y conocimientos recopilados en el pasado con objeto de hacer avanzar el conocimiento.

No es posible agotar el tema, sin embargo creo que puede ya apreciarse la inmensa complejidad de tópicos que deben considerarse al momento de emprender proyectos de preservación documental digital. El reto para resolver estas tareas no es nada fácil. El proceso de digitalización documental y su preservación para uso posterior es un desafío que implica amplios conocimientos tanto teóricos como metodológicos; decisiones delicadas y fuertes inversiones en tecnología y en recursos humanos calificados; serias limitaciones legales, obsolescencia de dispositivos, reconversiones de tiempo en tiempo, riesgos, y el hecho de que el tratamiento del problema requiere de un enfoque multi y transdisciplinario. Muchos responsables de acervos han postpuesto su decisión de emprender proyectos de preservación documental digital confiando en que llegará un momento en que la tecnología y los costos se volverán estables y competitivos, sólo para darse cuenta de que a pesar de que la tecnología y sus costos mejoran cada día, la cantidad y variedad de materiales a digitalizar sigue creciendo en forma exponencial, y disuelve esa confianza. No es en absoluto recomendable esperar a que los parámetros se estabilicen totalmente y los riesgos desaparezcan porque eso no está sucediendo. Es necesario preservar ahora, y no hay otras alternativas que nos permitan ignorar o soslayar este camino tecnológico. Y si hay que recorrer ese camino es indispensable entender el fenómeno ahora y empezar a prepararnos ya para enfrentar estos procesos conociendo bien los riesgos y los vericuetos para evitar cometer errores haciéndolo bien todo desde el comienzo, sin incurrir en costos o riesgos innecesarios y en lo posible sin cometer errores que a la larga debamos lamentar y/o corregir.

Es todavía común, sobre todo en nuestro medio mexicano, que muchos bibliotecarios y archivistas profesionales tiendan todavía a menospreciar el 
medio electrónico. Diversas razones, -válidas y no- les permiten voltear sólo a ver la construcción de acervos documentales únicamente bajo soportes "tradicionales". Bajo la premisa de que "lo que no está impreso no está publicado", simplemente tienden a ignorar el material digital en la red por considerarlo fútil, etéreo y riesgoso. Es cierto, la $\mathrm{Web}$, como un todo no es una biblioteca digital en sí misma, pero también es un hecho incuestionable que todas las bibliotecas digitales forman parte de la Web, así como una muy considerable parte de los archivos digitales.Y si todas las bibliotecas y esos archivos digitales forman parte de la Web, millones de documentos perfectamente válidos forman ya parte de acervos de bibliotecas y archivos, ahora electrónicos. Pero esos millones de documentos son ya "formales" -y digo formales porque forman parte del acervo de esas colecciones digitales-, en tanto que muchos millones más de documentos "informales" están en riego de perderse -y se pierden- con sobrecogedora frecuencia, precisamente por no querer, no saber o no poder hacer nada al respeto. Y si es el gran público el que no quiere, no sabe o no puede, es grave; pero el hecho de que esta situación se dé entre los profesionales de la información, es simplemente inadmisible.

Hemos podido observar claramente cómo a nivel mundial la preocupación y proyectos tendientes a estudiar y trabajar esta problemática siguen en aumento. Ahí están las grandes iniciativas norteamericana y de la unión europea, y están también las nacionales de gran visión y alcance, como la australiana, la canadiense y la holandesa, por citar algunas. Pero en México no contamos con ningún proyecto, programa, plan, iniciativa ni organización que esté trabajando en este rubro a gran escala. Todos los que existen son proyectos puntuales a nivel de ciertas instituciones puntuales. Reitero, nada se hace a nivel estratégico ni de alcance nacional. El factor cultural nos afecta a todos gravemente para empezar; la falta de sensibilidad existe a todos los niveles. Las instituciones que tienen entre sus deberes la preservación de algún acervo documental lo hacen principalmente con sus soportes "tradicionales"; pero muy rara vez o en muy bajo porcentaje, con sus acervos digitales; y por lo mismo no están resolviendo el problema, por lo que hemos creado un enorme rezago como país en este sentido. Pero no debemos culpar a estas instituciones. Como hemos analizado la problemática que enfrentamos con este tipo de proyectos es formidable; no pueden ser solucionados a nivel de organizaciones aisladas por esto rebasa sus capacidades; debemos enfrentar el problema como nación, como región latinoamericana o al menos como grandes consorcios, y contar con el concurso de múltiples sectores públicos y privados, además del académico.

Y lo mismo sucede con las personas que habrán de participar en ellos; este tipo de proyectos deben ser tratados con enfoques trans y multidisciplinarios 
además de requerir el concurso de personas en muy variados sectores para realmente obtener un adecuado diseño y puesta en marcha de un plan integral y armónico.

La preservación digital no es sólo un simple problema de tecnología y su obsolescencia; no es un problema cuya solución sea simplemente ir convirtiendo todo lo que teníamos en papel en archivos digitales. Tampoco se trata de solamente almacenar documentos. Implica a toda una escuela de pensamiento cuyo objetivo central pretende llevar materiales documentales hacia el largo plazo, muy largo plazo; idealmente a perpetuidad; su hilo conductor conlleva la organización y observancia cuidadosa de procedimientos de gestión documental que involucren a todo el ciclo de vida de la información. Es por ello muy importante concientizarnos de que la preservación digital no es nada más un método para mantener archivos de bits legibles y utilizables mañana, sino todo un proceso cultural y social que debe interactuar orquestada y armónicamente con una completa variedad de servicios que deberán apoyar los ambientes de la información documental contemplando, resolviendo e integrando todos sus aspectos: técnicos, legales y económicos; todo dentro de un contexto de utilidad social. Hablamos entonces un proceso cultural y social, que tiene que involucrar a diversos actores de variados sectores de la sociedad: autores, editores, bibliotecarios, archivistas, gobernantes, legisladores, informáticos, planeadores, tomadores de decisiones, etcétera, y repartir entre ellos armónica y equitativamente la responsabilidad que a cada uno le compete, en especial, pensamos en su responsabilidad social. Pero pone a todas las dificultades, los riesgos y los costos de preservar, es imposible soslayar el problema. Todos los conglomerados humanos, todas las regiones y países poseen riquezas documentales que necesariamente hay que preservar y distribuir; forman en esencia su patrimonio cultural y México no es la excepción. Y nuestro patrimonio cultural y documental es enorme, rico y variado. Es impensable no considerarlo y no tratar de preservarlo.

Los aspectos sociales de la preservación documental deben analizarse siempre junto con los demás aspectos para tener una visión completa de ella. Estos proyectos no pueden ser vistos sólo desde enfoques administrativos, tecnológicos o legales, debemos siempre agregarles el enfoque de las personas y su contexto social. Debemos poder garantizar siempre el acceso y la usabilidad documental para la generación actual y las futuras. Es imperativo establecer los principios, valores y premisas para que en un futuro el público pueda tener un acceso efectivo y masivo a esa información, y debemos velar siempre porque así suceda, sobre todo entre profesionales de la información. Hay un principio social básico que rige este aspecto: "de nada sirve preservar por preservar la información si nadie, -o muy pocos- tendrán acceso a 
ella". Salvados los aspectos técnicos, de propiedad intelectual y financieros que hay que cubrir para que la información se preserve, el reto máximo para el futuro será cómo hacer llegar esa información digital a un número mayor de personas en el mundo sin crear nuevas brechas segregacionistas. Como establecimos, no deseamos que la preservación digital sea uno más de los elementos que amplíen la "brecha digital" y sus consecuencias. Debemos pensar ahora en cómo crear las infraestructuras para garantizar que las personas tengan acceso a esa información en el futuro y que la brecha tienda a cerrarse.

Una última reflexión: si queremos realmente vivir en una sociedad de la información, -o mejor aún, del conocimiento-, tendremos y tenemos que construirla día a día, con todo nuestro empeño; no porque sea una moda, no por devoción a la tecnología, sino porque creemos que ésta puede cambiar nuestra realidad para bien. Habremos de asimilarla, deberemos trabajar en lo individual y lo colectivo para aspirar a que todos y cada uno seamos capaces de acceder, identificar, procesar, comprender, transformar, producir, difundir y utilizar información destinada a crear conocimientos, y a aplicarlos en beneficio propio y de la comunidad. Estando conscientes de que la información y sus tecnologías no pueden por sí mismas hacer las veces de un proyecto social común, debemos aceptar que en la actualidad tampoco puede haber un proyecto social común sin información. Por lo mismo es muy importante decidir para qué utilizaremos la información en un proyecto social; ésta es una herramienta y por lo mismo su uso tiene riesgos y potencialidades. La información es un recurso muy valioso hoy en día y como tal hay que tratarlo; no debemos ni malgastarlo, desperdiciarlo, llevarlo a extremos consumistas, ni prostituirlo o elitizarlo. Debemos tener que poder hacer ya una propuesta humanista de una sociedad tecnificada. Debemos pensar en cómo utilizar este recurso de forma eficaz y eficiente para lograr verdaderamente una sociedad de saberes y valores compartidos, en la que se privilegian los contenidos, la libertad de expresión, el libre acceso a las ideas y el conocimiento universales, el espíritu colaborativo, el respeto a la persona y a la naturaleza, la identidad y pluralidad culturales, la tolerancia y la responsabilidad social. No podemos dejar que este recurso se quede en una simple accesibilidad y comodidad tecnológica que marque un estatus social. Si nos preocupamos, -y nos ocupamos-, ésta puede ser nuestra oportunidad para dar un paso trascendental en la construcción de una sociedad moderna en donde realmente logremos construir un entorno propicio para la comunicación humana, en donde con ella podamos crear, aprender, crecer y progresar todos; en suma: ser y hacer juntos, como una sola sociedad, como una sola humanidad, como una sola, enorme, aldea global. 


\section{REFERENCIAS BIBLIOGRÁFICAS}

(Todas las referencias electrónicas han sido verificadas como existentes y exactas hasta el 1 de agosto del 2008).

Beagrie, Neil 2003, "National Digital Preservation Initiatives: An Overview of Developments in Australia, France, the Netherlands, and the United Kingdom and of Related International Activity: Commissioned for and sponsored by the National Digital Information Infrastructure and Preservation Program, Library of Congress", Council on Library and Information Resources (CLIR), CLIR publication Núm. 116, April 2003, 61 pp. ISBN 1-932326-006. Disponible agosto 1, 2008 en: http://www.clir.org/pubs/reports/pub116/pub116.pdf

"CLIR HISTORY" 2005, Sitio oficial del "Council on Library and Information Resources - CLIR”, disponible agosto, 2008 en: http:// www.clir.org/about/history.html

Commission on Preservation and Access 1996, "The Digital Preservation Consortium Mission and Goals", Sitio oficial del "Council on Library and Information Resources - CLIR", disponible agosto 1, 2008 en: http://www.clir.org/pubs/reports/dpcmiss/dpcmiss.ht$\mathrm{ml}$

Comunidad Económica Europea, Programa IDA, Interchange of Data between Administrations, 2001, "MoReq. Modelo de Requisitos para la Gestión de Documentos Electrónicos de Archivo, Bruselas, Marzo 2001, disponible agosto 1, 2008 en: http://dglb.cult. gva.es/ArxiuRegne_v/documents/moreq.pdf

Digital Preservation Europe, 2006, "DPE Objectives”, Sitio oficial de la DPE, disponible agosto, 2006 en: http://www.digitalpreservationeurope.eu/about/objectives/; http://www.ala.org/ala/alonline/ selectedarticles/10reasonswhy.cfm

IFLA - International Federation of Library Associations- 2006, "Manifiesto de la IFLA/UNESCO Sobre Internet : Directrices". Compilado y Editado por Seidelin, Susanne, Directora de la Oficina IFLA/ FAIFE, Septiembre 2006, Página Oficial de la IFLA, disponible agosto 1, 2008 en: http://www.ifla.org/faife/policy/iflastat/Internet-ManifestoGuidelines-es.pdf

Kenney, Anne R. y Buckley, Ellie 2005, "Developing Digital Preservation Programs: the Cornell Survey of Institutional Readiness, 2003-2005 ", en: "RLG Diginews". RLG's Online Newsletter for Digital Imaging and Preservation, Aug. 15, 2005, disponible agosto 1, 2008 en: http://www.rlg.org/en/page.php?Page_ID =20 744 
Library of Congress 2003, "NDIIPP: The National Digital Information Infrastructure \& Preservation Program”, Sitio Oficial de la Biblioteca del Congreso de los E.U.A., disponible agosto, 2008 en: http://www.digitalpreservation.gov/library/program_back.html

National Archives and Records Administration 2003, ERA Project, Sitio Oficial del proyecto, disponible agosto 2008 en: http://www. archives.gov/about/plans-reports/strategic-plan/2003/index.html

NSF-DLI - National Science Foundation - Digital Libraries Initiative 2003, "Invest to Save: Report and Recommendations of the NSFDELOS Working Group on Digital Archiving and Preservation", 2003, disponible agosto 1, 2008 en: http://eprints.erpanet.org/48 /01/Digitalarchiving.pdf

OCLC / RLG, 2001, "Preservation Metadata for Digital Objects: A Review of the State of the Art", White Paper, OCLC-RLG Preservation Metadata Working Group, January 2001, disponible agosto 1, 2008 en: http://www.oclc.org/research/projects/pmwg/presmeta_wp.pdf

RLG / OCLC 2001, "Trusted Digital Repositories: Attributes and Responsibilities", RLG / OCLC, Mountain View, VS, May 2002, disponible agosto 1, 2008 en: http://www.oclc.org/programs/ourwork/past/trustedrep/repositories.pdf

Rodríguez G., Adolfo 2006, "La Brecha Digital y Sus Determinantes", México: UnAM, Centro Universitario de Investigaciones Bibliotecológicas, 254 p. ISBN: 970-32-3853-X.

UNESCO 2002, "Declaración Universal de la UNESCO Sobre la Diversidad Cultural", Página Web Oficial de la UNESCO, disponible agosto 1, 2008 en: http://www.unesco.org/culture/pluralism/diversity/html_sp/index_sp.shtml

United States Congress 2000, "National Digital Information Infrastructure and Preservation Program", Public Law 106-554. 106th Congress. December 14th, 2000, disponible agosto 1, 2008 en: http://frwebgate.access.gpo.gov/cgi-bin/getdoccgi?dbname $=106$ _cong_public_laws\&docid=f:publ554.106

Voutssás M., Juan 2006, "Bibliotecas y Publicaciones Digitales", México : UNAM, Centro Universitario de Investigaciones Bibliotecológicas, 342 p. ISBN:970-32-3962-5.

2007, "Un Modelo de Planeación de Bibliotecas Digitales Para México", México: UNAM, Centro Universitario de Investigaciones Bibliotecológicas, 309 p. ISBN: 970-32-4111-5.

Webb, Colin [et al] 2003, "Directrices Para la Preservación del Patrimonio Dgital”, UNESCO, Information Society Division. Preparado por Colin Webb en la Biblioteca Nacional de Australia, Marzo 2003, Documento núm. CI-2003/Ws/3, Sitio oficial de UNESCO, disponible agosto 1, $2008 \mathrm{en:} \mathrm{http://unesdoc.unesco.org/images/}$ 0013/001300/130071s.pdf 
"Workshop on Issues in the Field of National Deposit Collections of Electronic Publication" 1995, European Commission. DG Information Society, Luxembourg, December 18, 1995, disponible agosto 1, 2008 en: http://cordis.europa.eu/libraries/en/depo-rpt. html

World Summit on the Information Society (WSIS) 2003, Cumbre Mundial sobre la Sociedad de la Información, "Declaración de Principios”, Ginebra, Diciembre 10-12, 2003, disponible agosto 1, 2008 en: http://www.itu.int/dms_pub/itu-s/md/03/wsis/doc/S0 3-WSIS-DOC-0004!!pdf-S.pdf 
